\title{
Nimodipine inhibits AP firing in cultured hippocampal neurons predominantly due to block of voltage-dependent potassium channels
}

\author{
Anton Caro ${ }^{1}$, Bohumila Tarabova ${ }^{1,3}$, Jonathan Rojo-Ruiz ${ }^{2}$ and Lubica Lacinova ${ }^{1}$ \\ ${ }^{1}$ Institute of Molecular Physiology and Genetics, Slovak Academy of Sciences, Bratislava, Slovak Republic \\ ${ }^{2}$ University of Torino, Department of Neuroscience, Torino, Italy \\ ${ }^{3}$ Technische Universität Kaiserslautern, Erwin Schrödinger-Straße 13, Kaiserslautern, Germany
}

\begin{abstract}
L-type calcium channels (LTCC) are important functional elements of hippocampal neurons contributing to processes like memory formation and gene expression. Mice lacking the $\mathrm{Ca}_{\mathrm{V}} 1.2 \mathrm{channel}$ in hippocampal pyramidal cells exhibited defects in spatial memory (Moosmang et al. 2005) and lowered frequency of repetitive action potential (AP) firing (Lacinova et al. 2008). We tested the contribution of LTCC to AP firing of cultured rat neonatal hippocampal neurons using the dihydropyridine channel blocker nimodipine. Ionic currents and APs were recorded in the whole cell patch clamp configuration. A prolonged depolarizing current pulse activated the firing of a series of APs. The presence of 10 $\mu \mathrm{M}$ nimodipine blocked all but the first AP in series. This concentration, which is potent enough to completely block LTCC, inhibited about $35-50 \%$ of the total calcium current. In addition, nimodipine blocked about $50 \%$ of both calcium-dependent and voltage-dependent potassium currents whereas the sodium current was not affected. We suggest that nimodipine suppressed the firing of APs in cultured neonatal rat hippocampal neurons due to inhibition of both calcium and potassium currents.
\end{abstract}

Key words: Hippocampal neurons - Nimodipine - Potassium current - Calcium current - Action potential

Abbreviations: AP, action potential; DHP, dihydropyridine; LTCC, L-type calcium channel.

\section{Introduction}

The hippocampus is a brain region participating in the formation of explicit memory, i.e. memory of facts and places (reviewed in Kandel 2009). The decisive element of memory forming is an activity-dependent strengthening of synaptic transmission, the so-called long term potentiation (LTP) (Bliss and Lomo 1973). Two phases of LTP can be distinguished: an early phase requiring covalent protein modification and a late protein synthesis-dependent phase (Frey et al. 1988). L-type calcium channels (LTCC) contribute to several memoryforming pathways, e.g., the cAMP response element-binding protein pathway (Deisseroth et al. 2003), Hebbian synaptic plasticity (Grover and Teyler 1990; Bauer et al. 2002; Moos-

Correspondence to: Lubica Lacinova, Institute of Molecular Physiology and Genetics, Slovak Academy of Sciences, Bratislava, Slovak Republic

E-mail: lubica.lacinova@savba.sk mang et al. 2005) or transcription of brain-derived neurotrophic factor (Murphy et al. 1991; West et al. 2001).

The prevalent LTCC isoform expressed in hippocampus is the Ca 1.2 isoform (Hell et al. 1993; Sinnegger-Brauns et al. 2004). Absence of the $\mathrm{Ca}_{\mathrm{V}} 1.2$ channel in adult mouse hippocampus resulted in defects of late phase LTP and deficits of spatial memory (Moosmang et al. 2005). LTCC may support LTP and consequently memory forming through back-propagated somatic action potentials (APs) (Spruston et al. 1995; Hoffman et al. 1997; Kampa et al. 2006). Somatic APs alone are sufficient to activate mechanisms supporting late-phase LTP and to convert early phase LTP into stable late LTP (Dudek and Fields 2002). Therefore the contribution of LTCC to shaping AP trains is of major interest.

Reported effects of dihydropyridine (DHP) LTCC blockers on hippocampal excitability are controversial. In rabbit CA1 pyramidal hippocampal neurons, nimodipine increased excitability by increasing the number of APs and by decreasing accommodation frequency during a prolonged depolarizing cur- 
rent pulse (Moyer et al. 1992). This effect was more pronounced in neurons from aging than from young animals. In adult rat CA1 neurons the effect was opposite as $10 \mu \mathrm{M}$ nimodipine substantially reduced the number of induced APs (Magee and Carruth 1999). Nevertheless, another group did not find any effect of anorganic calcium channel blockers on AP firing in rat adult CA1 cells (Azouz et al. 1996). In CA1 pyramidal neurons from young (P8-P25) rats, 10-100 $\mu \mathrm{M}$ nimodipine suppressed AP bursting (Chen et al. 2005). In adult mouse hippocampal CA1 neurons, $10 \mu \mathrm{M}( \pm)$ isradipine only moderately slowed the frequency of AP firing (Lacinova et al. 2008).

Here we tested the effect of the DHP LTCC blocker nimodipine on repetitive AP firing in a primary culture of neonatal rat hippocampal neurons. We have shown that 10 $\mu \mathrm{M}$ nimodipine substantially suppresses generation of AP trains. This effect was mediated by inhibition of LTCC and multiple potassium channels.

\section{Material and Methods}

\section{Cell isolation and culture}

Primary cultures of neonatal rat hippocampal neurons were prepared from 1-2 days old rats. Meninge-free hippocampi were microdissected in ice-cooled sterile phosphate buffer saline (PBS) supplemented by filtered foetal serum albumin and glucose. Isolated hippocampi were incubated for $20 \mathrm{~min}$ at $37^{\circ} \mathrm{C}$ in $5 \mathrm{ml} \mathrm{PBS}$, supplemented by $2 \mu \mathrm{g}$ papain and $5 \mu \mathrm{g}$ foetal serum albumin. The slices were washed in PBS and triturated in Neurobasal A medium supplemented with 2\% B27, 1\% penicillin-streptomycin and $1 \%$ L-glutamine. The cell suspension was spinned at $1000 \mathrm{rpm}$ and the cells were resuspended in culture medium (Neurobasal A medium supplemented with $2 \%$ B-27 supplement, $1 \%$ penicillin streptomycin and $1 \% \mathrm{~L}$-glutamine). Cells were plated at density of $5 \times 10^{4} / \mathrm{ml}$ of media on L-polylysin-coated glas coverslips. Half of the medium was changed every third day.

\section{Electrophysiological recordings}

For recording, large neurons of pyramidal shape and welldefined dendrite processes were used. The cell culture was maintained for two weeks. The neurons required at least three days to recover after the isolation. Whole cell currents and APs were measured starting on day 4 (D4) after isolation using an EPC 10 patch clamp amplifier (HEKA Electronic, Pfalz, Germany). Series resistance and cell capacitance were compensated by built-in circuits of the EPC 10 amplifier.

The following solutions were used in experiments: for measurements of potassium currents and APs, the pipette solution contained (in mM): KCl 130, MgATP 3, NaGTP 0.4, HEPES 25, EGTA 10, pH 7.2 (KOH); the bath solution contained (in
$\mathrm{mM}$ ): $\mathrm{NaCl} 150, \mathrm{KCl} 4$, HEPES 10, $\mathrm{CaCl}_{2} 2, \mathrm{MgCl}_{2}$ 1, glucose $10, \mathrm{pH} 7.4(\mathrm{NaOH})$. In part of the measurements of potassium currents calcium was omitted from the bath solution. For measurements of calcium currents, the pipette solution contained (in mM): CsCl 105, TEACl 20, EGTA 10, $\mathrm{MgCl}_{2} 1$, NaATP 4, NaGTP 0.5, glucose 10, pH 7.4 (CsOH); bath solution contained (in mM): $\mathrm{NaCl} 140, \mathrm{BaCl}_{2} 5, \mathrm{MgCl}_{2}$, HEPES 10 , glucose $10, \mathrm{pH} 7.4(\mathrm{NaOH})$. For measurements of sodium currents pipette solution contained (in $\mathrm{mM}$ ): $\mathrm{CsCl} 130$, TEACl 10, EGTA 10, $\mathrm{MgCl}_{2}$ 5, $\mathrm{Na}_{2}$ ATP 5, HEPES 10, pH 7.4 $(\mathrm{CsOH})$; bath solution contained (in mM): TEACl 125, NaCl $10, \mathrm{CsCl} 25, \mathrm{CaCl}_{2}$ 2, HEPES 10, glucose 10, $\mathrm{pH} 7.4(\mathrm{NaOH})$. The osmolarity of the pipette solution was approximately 315 $\mathrm{mosmol} / \mathrm{kg}$. The initial osmolarity of the bath solution ranged from 290 to $300 \mathrm{mosmol} / \mathrm{kg}$. The final osmolarity of the bath solutions was adjusted by adding glucose until the osmolarity of the bath solution was approximately $3 \mathrm{mosmol} / \mathrm{kg}$ smaller than the osmolarity of the pipette solution.

Ion currents and APs were measured in the whole cell patch clamp configuration. The holding potential was set to $-80 \mathrm{mV}$ for measurements of calcium and sodium currents and to $-60 \mathrm{mV}$ for measurements of potassium currents. In current clamp, the holding current was injected so that the membrane potential was fixed at about $-70 \mathrm{mV}$. Single APs were activated by 5-ms-long depolarizing current pulses with amplitudes increasing in steps of $25 \mathrm{pA}$. A similar protocol was used for measurement of AP series except that pulse length was $300 \mathrm{~ms}$.

A stock solution of nimodipine was prepared in ethanol at a concentration of $10 \mathrm{mmol} / 1$ and stored at $-20^{\circ} \mathrm{C}$. It was diluted in the bath solution at a final concentration of 10 $\mu \mathrm{mol} / \mathrm{l}$ prior to each experiment. This solution was applied in close proximity of the cell investigated by a gravity-driven solution exchanger.

\section{Data acquisition and processing}

Data were recorded using the HEKA software Patchmaster. For off-line data analysis, Fitmaster (HEKA) and Origin 8.1 (Microcal) were used. Results are presented as mean \pm S.E.M. with the number of tested cells in brackets. Statistical significance was estimated using paired or unpaired Student's $t$-test as appropriate. A difference was considered significant if $p<0.05$.

\section{Results}

\section{Basic properties of cultured hippocampal neurons}

Primary cultures of neonatal rat neurons were established on postnatal day P1 or P2 and were maintained up to two weeks. Cells were allowed to recover for four days after iso- 

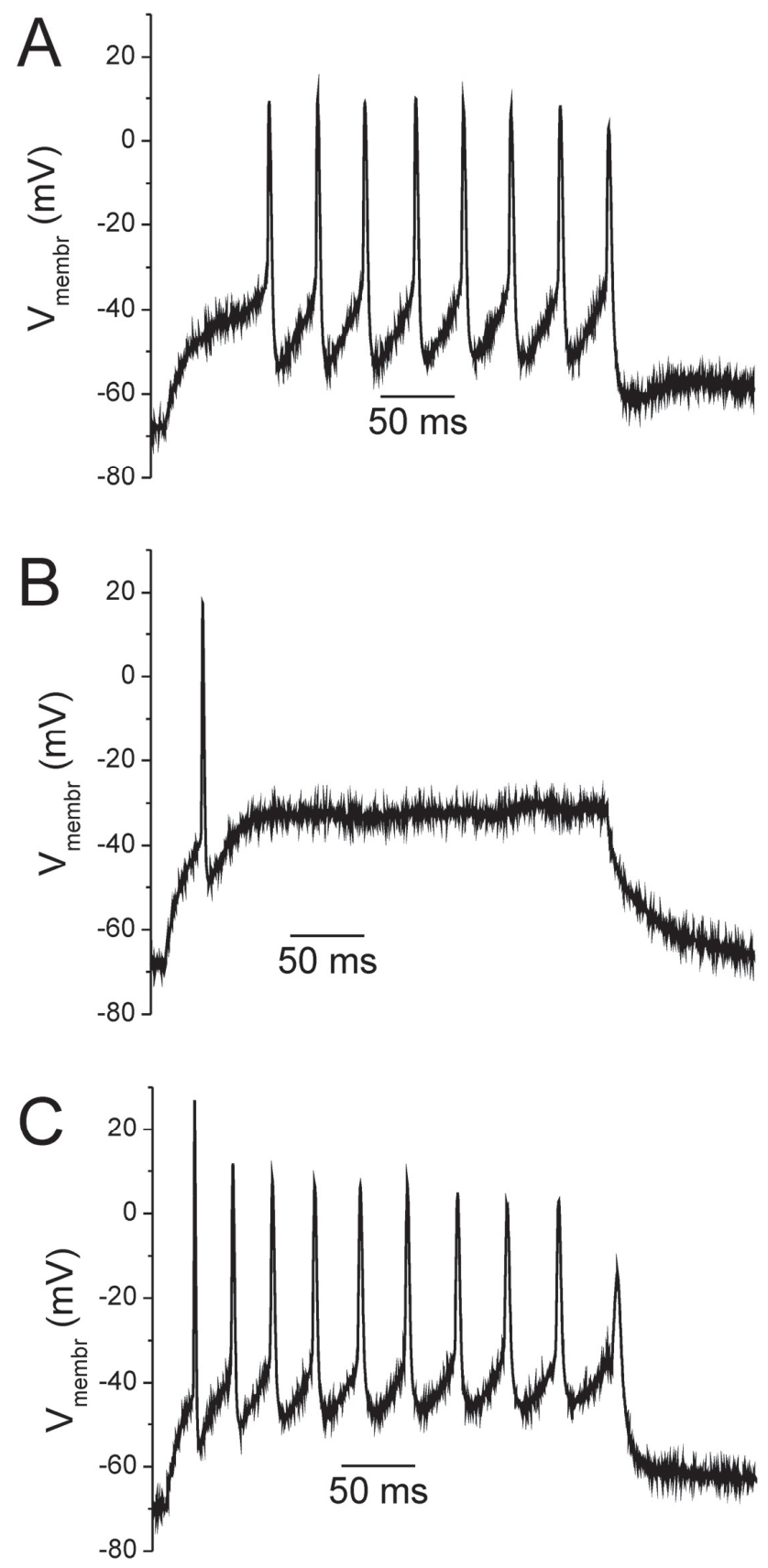

Figure 1. Nimodipine suppression of repetitive AP firing. Repetitive AP firing in cultured hippocampal neurons was activated by 300 ms-long rectangular depolarizing current pulses from a holding current adjusted so that the resting membrane potential of each cell investigated was $-70 \mathrm{mV}$. The same current clamp protocol was applied under control conditions (A), in the presence of $10 \mu \mathrm{M}$ nimodipine (B) and after washout of nimodipine (C).

lation. Electrophysiological recordings were made starting at D4 of cell culture up to D11. Barium currents through calcium channels were detected during the whole period.
The average current density ranged between 80 and 100 $\mathrm{pA} / \mathrm{pF}$ with a slight trend to increase with prolonged time in culture. A brief $(5 \mathrm{~ms})$ depolarizing current pulse activated the firing of a single AP. The time course, voltage threshold and amplitude of such AP did not change during this time span (data not shown).

\section{Nimodipine suppressed repetitive firing of APs}

The principle type of activity of hippocampal neurons is repetitive AP firing. A 300-ms-long depolarizing current pulse activated the firing of a series of APs (Fig. 1A). Application of $10 \mu \mathrm{M}$ nimodipine inhibited all but the first $\mathrm{AP}$ in series and decreased the extent of afterhyperpolarization (Fig. 1B). AP firing was fully restored after 90 to $120 \mathrm{~s}$ of nimodipine washout (Fig. 1C). The effect was independent of the time in culture. The same observation was made on D5 $(n=5)$, D6 $(n=6), \mathrm{D} 7(n=7), \mathrm{D} 8(n=7), \mathrm{D} 9(n=8), \mathrm{D} 10(n=5)$ and $\mathrm{D} 11(n=6)$.

The proportion of barium current carried through L-type calcium channels decreased with time in culture

To assess the contribution of LTCC to the total barium current flowing through calcium channels, we have used $10 \mu \mathrm{M}$ nimodipine for its inhibition. This concentration is sufficient to fully block both $\mathrm{Ca}_{V} 1.2$ and $\mathrm{Ca}_{V} 1.3$ LTCC, which are known to be expressed in hippocampal neurons. Approximately $50 \%$ of the barium current was carried through LTCC as demonstrated by its inhibition by nimodipine (Fig. $2 \mathrm{~A}$ and B). Later (D8-D11), the proportion of LTCC significantly decreased to about $35 \%$ (Fig. 2).

\section{Nimodipine did not affect the sodium current}

The substantial inhibition of repetitive AP firing could include other factors than block of LTCC alone. The hyperpolarization following the first fired AP was lower (Fig. 1) but still may have been sufficient for activation of the sodium current. It was reported that in some cases the sodium current may be blocked by dihydropyridines (DHP) (Inoue et al. 1999; Yatani and Brown 1985). Nevertheless, $10 \mu \mathrm{M}$ nimodipine did not affect the sodium current in cultured neonatal rat hippocampal cells (Fig. 3). For these experiments we lowered the concentration of sodium ions in the bath solution to $10 \mathrm{mM}$ (see Material and Methods) in order to lower the sodium current amplitude to values enabling voltage clamping.

\section{Nimodipine inhibited the outward potassium current}

The reduced hyperpolarization following the first AP suggested that nimodipine might inhibit voltage-dependent potassium channels. Indeed, $10 \mu \mathrm{M}$ nimodipine suppressed part of the 

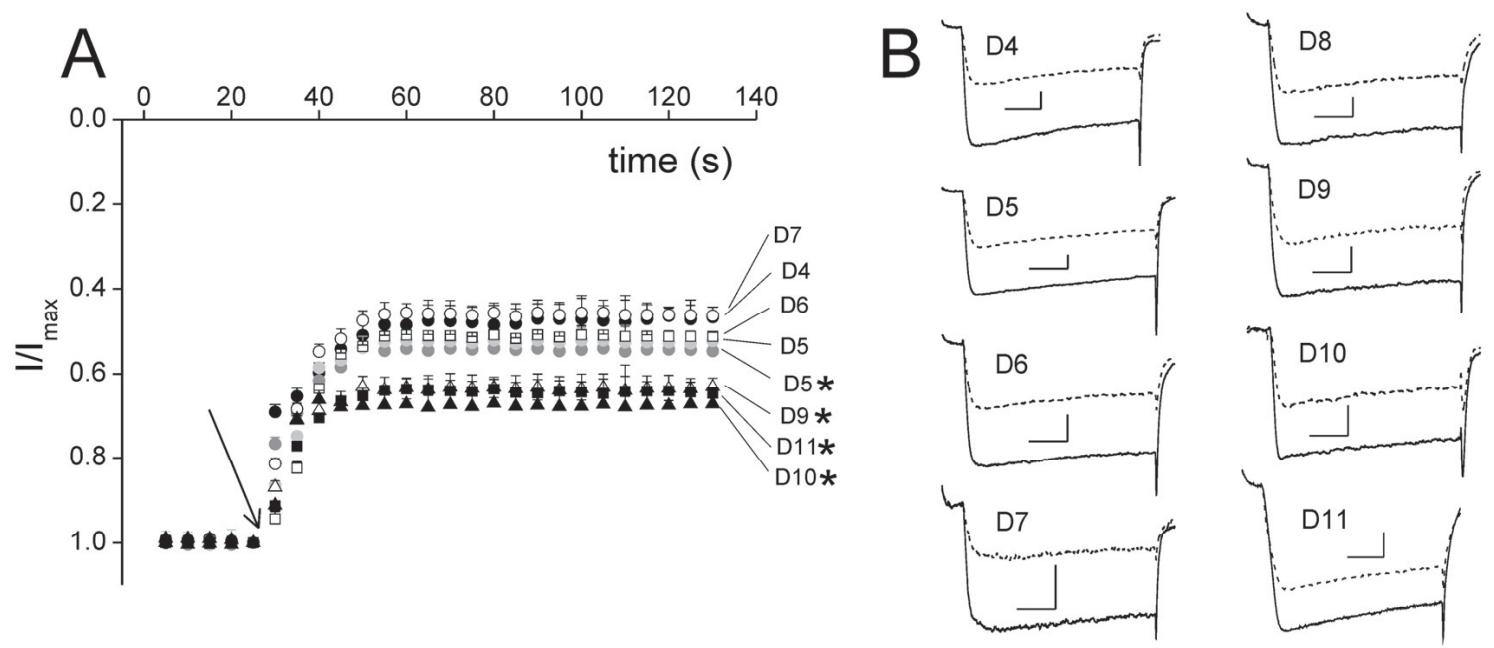

Figure 2. Nimodipine inhibition of LTCC. A. Time courses of the amplitudes of barium currents through calcium channels before and during cell superfusion with $10 \mu \mathrm{M}$ nimodipine measured at days 5-11 after isolation as marked. Time courses were normalized with respect to the maximal current amplitude for each individual cell and averaged. Nimodipine was added at time point marked by an arrow. Numbers of tested cells were as follow: D4 $(n=4)$; D5 $(n=5)$; D6 $(n=5)$; D7 $(n=10)$; D8 $(n=11)$; D9 $(n=7) ; \mathrm{D} 10(n=7)$; D11 $(n=3)$. During prolonged time in culture the proportion of the nimodipine-sensitive current decreased. This decrease was statistically significant starting with D8 ${ }^{*} p<0.05$ (Dn versus D4). B. Representative examples of current traces recorded in control conditions (solid lines) and after equilibrating with $10 \mu \mathrm{M}$ nimodipine (dashed lines) at days in culture marked next to each trace. Scale bars represent $10 \mathrm{~ms}$ (horizontal) and $250 \mathrm{pA}$ (vertical). Currents were activated by $50 \mathrm{~ms}$ long depolarizing pulses from a holding potential of $-80 \mathrm{mV}$ to $0 \mathrm{mV}$.

outward potassium current. Inhibition of the peak current amplitude was negligible, while almost $50 \%$ of the current at the end of 400-ms-long pulse to $+60 \mathrm{mV}$ was blocked (Fig. $4 \mathrm{~A}$ ). Potassium current inhibition developed more slowly than the inhibition of LTCC (Fig. 4A versus Fig. 2A). The current blocked by nimodipine was evaluated as difference between currents recorded in the absence and in the presence of $10 \mu \mathrm{M}$ nimodipine (Fig. 4B). This current activated slowly, did not inactivate during 500-ms-long depolarizations and exhibited weak outward rectification. The remaining current inactivated sharply within the first $100 \mathrm{~ms}$ of depolarization (Fig. 4B). A separate analysis of the current amplitude at the peak and at the end of 500-ms-long depolarizing pulse revealed minor (less than 10\%) inhibition of the peak current (Fig. 4C) and substantial (about $50 \%$ ) inhibition of the end current (Fig. 4D). The inhibition was only weakly voltage-dependent at depolarizations below 0 $\mathrm{mV}$ and voltage-independent at depolarizations above $0 \mathrm{mV}$ (Fig. 4C and D).

The effect of nimodipine on potassium currents was independent of calcium influx

Rat hippocampal neurons express $\mathrm{Ca}^{2+}$-dependent potassium channels dependent on calcium entry through voltage-activated calcium channels. To distinguish a potential indirect block of the calcium-activated potassium current due to block of the calcium current we repeated our experi- ments in a $\mathrm{Ca}^{2+}$-free solution. In the absence of $\mathrm{Ca}^{2+}$ ions in the extracellular solution, a current component with apparently slow activation kinetics was missing (Fig. 5A and B). The average peak current density was virtually identical in the presence and absence of $\mathrm{Ca}^{2+}$ (Fig. 5C). The average current density at the end of 300-ms-long pulse was by about $50 \%$ lower in the absence of calcium ions (Fig. 5D). Removal of calcium ions from the bath solution was similar to the

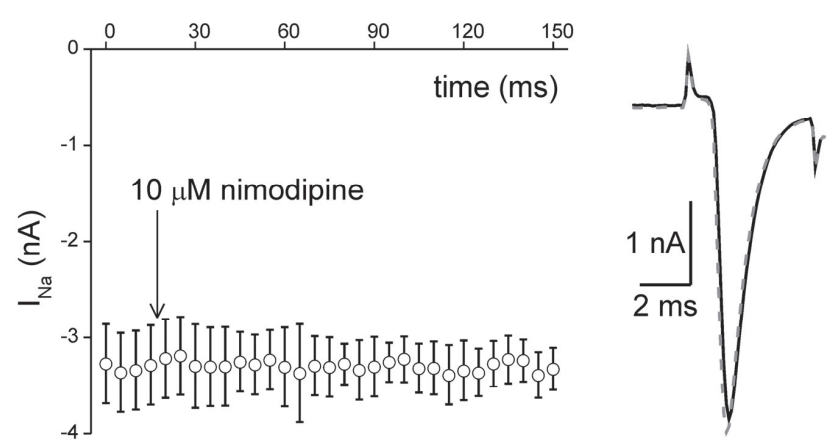

Figure 3. Lack of a nimodipine effect on sodium currents. Time course of the sodium current amplitude activated by $5 \mathrm{~ms}$ long depolarizing pulses from a holding potential of $-80 \mathrm{mV}$ to $0 \mathrm{mV}$. Cells were superfused with $10 \mu \mathrm{M}$ nimodipine from the moment marked by an arrow. Results from 4 cells were averaged. A representative example of current traces recorded in the absence (solid line) and presence (dashed line) of nimodipine is shown on right. 

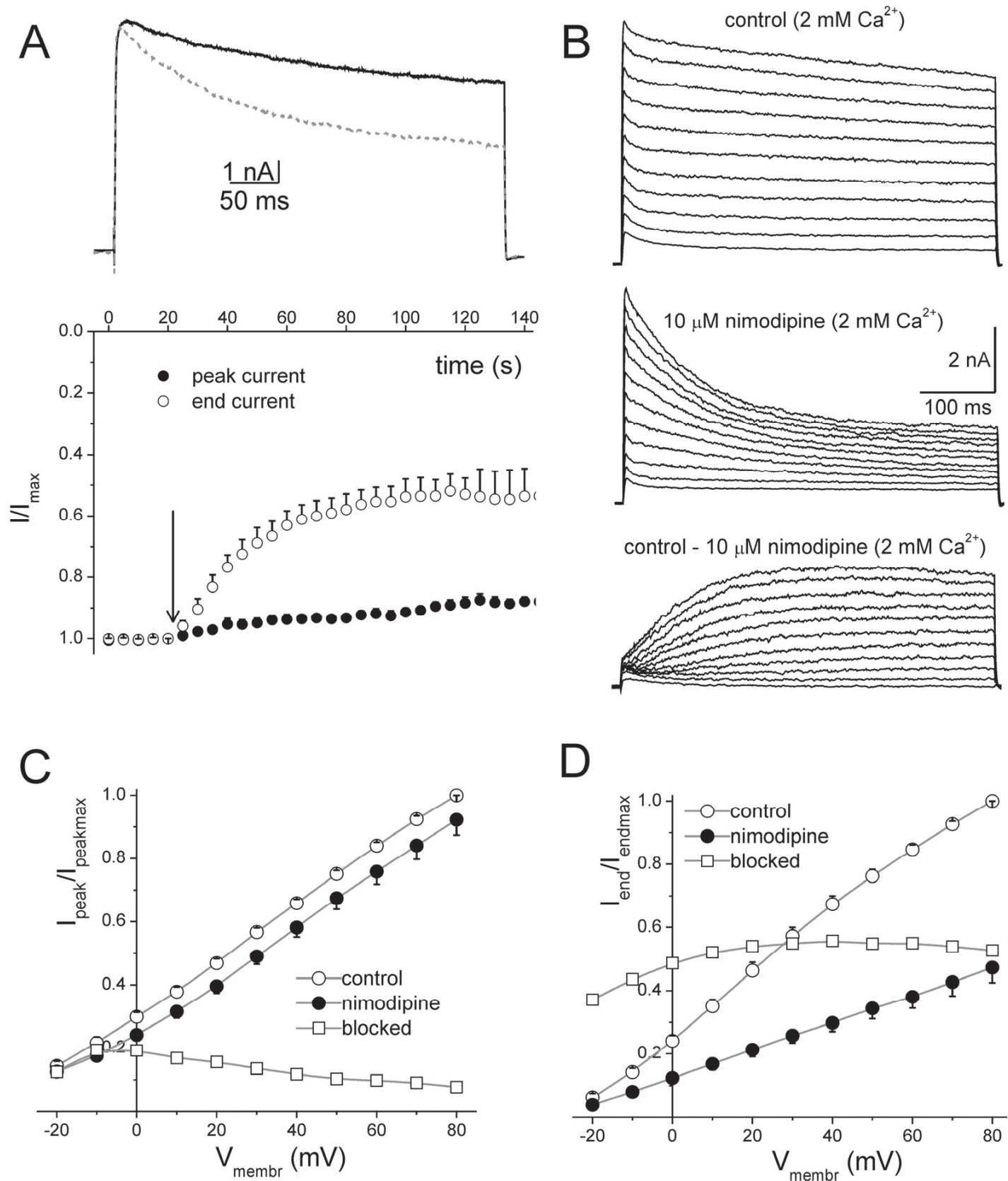

Figure 4. Block of potassium currents by nimodipine. A. Time course of the potassium current amplitude measured at the peak of the current trace (solid circles) and at the end of a $400 \mathrm{~ms}$ long depolarizing pulse to $+60 \mathrm{mV}$ (open circles). Results from 5 cells were averaged. At the moment marked by an arrow $10 \mu \mathrm{M}$ nimodipine were added. Representative example of current traces recorded in the absence (solid line) and presence (dashed line) of nimodipine are shown above the graph. B. representative examples of the currents recorded by a series of $500 \mathrm{~ms}$ long depolarizing pulses to membrane voltages between $-20 \mathrm{mV}$ and $+80 \mathrm{mV}$ in the absence (upper) and presence (middle) of $10 \mu \mathrm{M}$ nimodipine. Bottom traces were obtained by subtraction of traces recorded in the presence of nimodipine from traces recorded under control conditions and represent current blocked by nimodipine. C. amplitudes of potassium currents measured at a peak of each trace were normalized with respect to the peak current amplitude measured at $+80 \mathrm{mV}$ for each individual cell and then averaged ( $n=5$ ). $O$ peak I-V relation measured under control conditions; $-\mathrm{I}-\mathrm{V}$ relation measured in the presence of nimodipine; $\square$ proportion of peak current blocked by nimodipine calculated as $1-\left(\mathrm{I}_{\text {nimodipine }} / \mathrm{I}_{\text {control }}\right)$. D. Sustained potassium current amplitudes measured at the end of each trace were normalized with respect to the sustained current amplitude measured at the end of a pulse to $+80 \mathrm{mV}$ for each individual cell and then averaged. $O$ end I-V relation measured under control conditions; $-\mathrm{I}-\mathrm{V}$ relation for the sustained current measured in the presence of nimodipine; $\square$ proportion of the sustained current blocked by nimodipine calculated as $1-\left(\mathrm{I}_{\text {nimodipine }} / \mathrm{I}_{\text {control }}\right)$. 
effect of nimodipine (compare Fig. 4B and Fig. 5A and B). Therefore it could be expected that the inhibition of the voltage-dependent potassium current will be diminished in calcium-free solution. However, this was not the case. In calcium-free solution the potassium current was similar to that in $\mathrm{Ca}^{2+}$-containing solution (Fig. 6). Nimodipine inhibited a minor part of the peak current amplitude and a substantial portion of sustained current at the end of depolarizing pulse (Fig. 6A). Consistent with the inhibition of voltage-dependent potassium channels, the current inhibited by nimodipine activated rapidly and inactivated during a 300-ms-long depolarizing pulse (Fig. 6B). The inhibition of the peak current amplitude and of the sustained current at the end of the depolarizing pulse was voltage-independent for membrane depolarizations to $0 \mathrm{mV}$ and higher (Fig. 6D and E).

\section{Discussion}

Neuronal cells are complex systems expressing variety of ion channels depending on the species, tissue region and developmental stage. In this work we investigated the effect of the DHP calcium channel blocker nimodipine on the excitability of neonatal rat hippocampal neurons in primary culture. We have shown that $10 \mu \mathrm{M}$ nimodipine fully blocked repetitive AP firing evoked by a prolonged depolarizing current pulse. This finding is in line with several previous reports on the same species at different developmental stages. In hippocampal slices prepared from young (P8-P25) rats, $10 \mu \mathrm{M}$ nimodipine completely suppressed repetitive AP firing (Chen et al. 2005). Blockers of T-type $\left(\mathrm{Ni}^{+}\right)$and N/P/Q-type ( $\omega$-conotoxin MVIIC) calcium channels expressed in these neurons were less
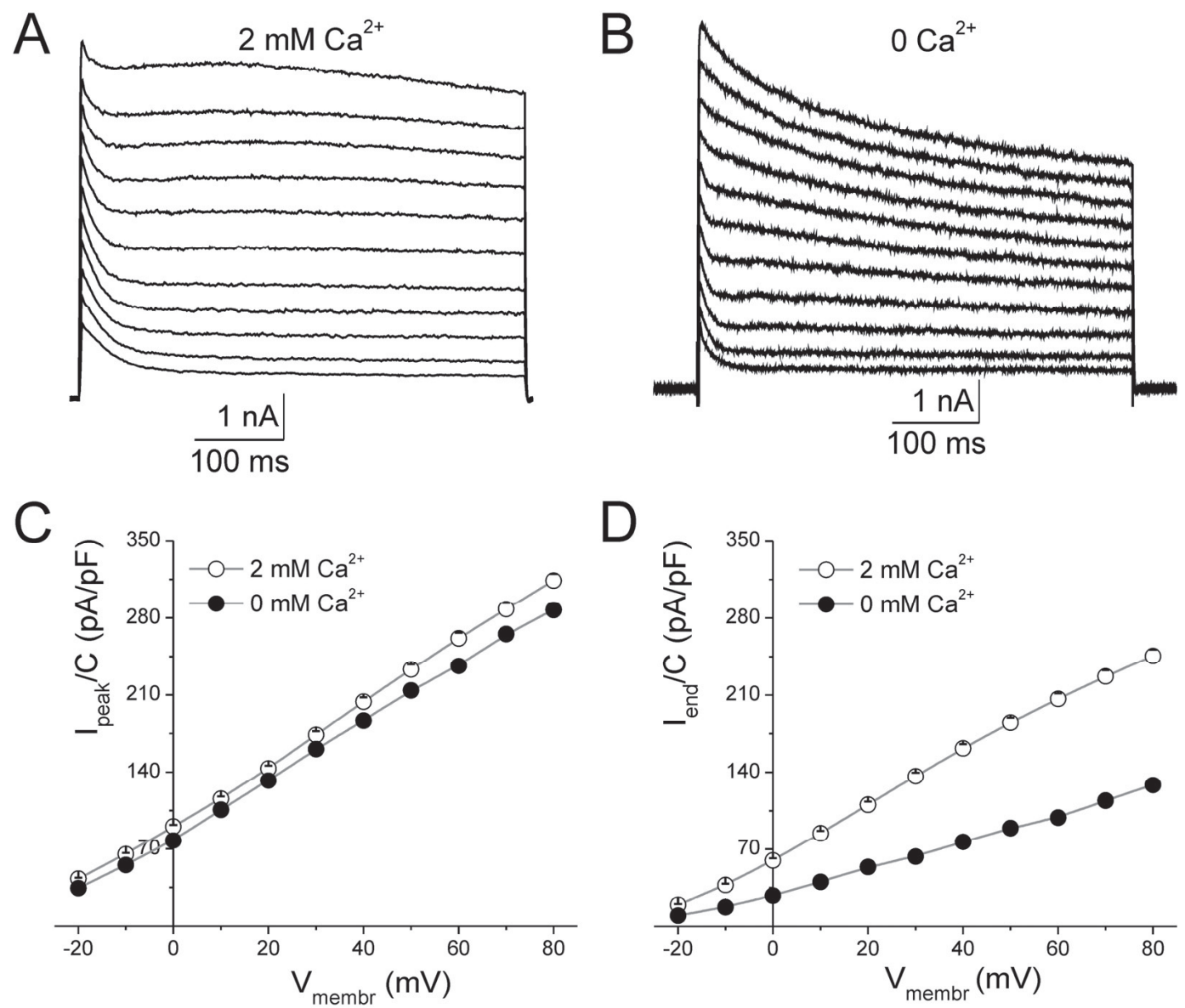

Figure 5. Outward potassium currents in the presence and absence of $\mathrm{Ca}^{2+}$. Representative example of potassium currents activated by a series of $500 \mathrm{~ms}$ long depolarizing pulses to membrane voltages between $-20 \mathrm{mV}$ and $+80 \mathrm{mV}$ with $2 \mathrm{mM} \mathrm{Ca}^{2+}$ in the bath solution (A) and in nominally calcium-free bath solution (B). C. Amplitudes of potassium currents measured at the peak of each trace were normalized with respect to the peak current amplitude measured at $+80 \mathrm{mV}$ for each individual cell and then averaged. $\mathrm{O}$ peak I-V relation measured in the presence of $\mathrm{Ca}^{2+}$ $(n=5)$; $-\mathrm{I}-\mathrm{V}$ relation measured in the absence of $\mathrm{Ca}^{2+}(n=3)$. D. Sustained potassium current amplitudes measured at the end of each trace were normalized with respect to the sustained current amplitude measured at the end of a pulse to $+80 \mathrm{mV}$ for each individual cell and then averaged. $\mathrm{O}$ end $\mathrm{I}-\mathrm{V}$ relation measured in the presence of $\mathrm{Ca}^{2+} ; \bullet \mathrm{I}-\mathrm{V}$ relation for the sustained current measured in the absence of $\mathrm{Ca}^{2+}$. 

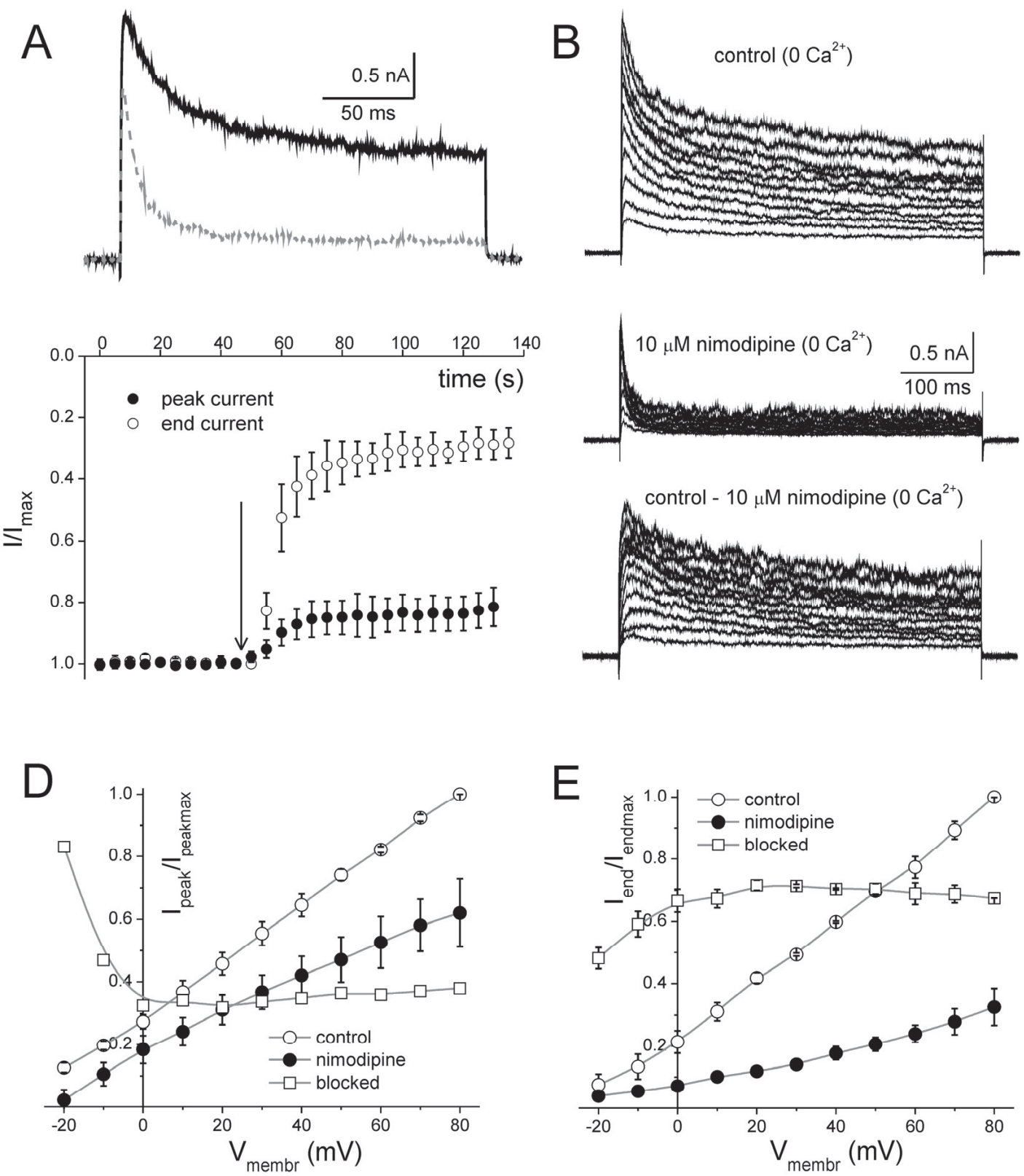

Figure 6. Potassium currents are blocked by nimodipine in $\mathrm{Ca}^{2+}$-free solution. The same experiments and analysis as in the Fig. 4 were done in the absence of $\mathrm{Ca}^{2+}$ in bath solution. A. Representative example of current traces recorded in the absence (solid line) and presence (dashed line) of nimodipine are shown in the upper part. The time course of the potassium current amplitude measured at the peak of current trace $(\bullet)$ and at the end of a $200 \mathrm{~ms}$ long depolarizing pulse to $+60 \mathrm{mV}(\mathrm{O})$. Results from 3 cells were averaged in this graph. At the moment marked by an arrow $10 \mu \mathrm{M}$ nimodipine were added. B. Representative examples of currents recorded in response to a series of $500 \mathrm{~ms}$ long depolarizing pulses to membrane voltages between $-20 \mathrm{mV}$ and $+80 \mathrm{mV}$ in the absence (upper) and presence (middle) of $10 \mu \mathrm{M}$ nimodipine. Bottom traces were obtained by subtraction of traces recorded in the presence of nimodipine from traces recorded under control conditions and represent the current blocked by nimodipine. C. Amplitudes of potassium currents measured at a peak of each trace were normalized with respect to the peak current amplitude measured at $+80 \mathrm{mV}$ for each individual cell and then averaged $(n=3)$. $\bigcirc$ peak I-V relation measured under control conditions $\left(0 \mathrm{Ca}^{2+}\right) ; \bullet \mathrm{I}-\mathrm{V}$ relation measured in the presence of nimodipine; $\square$ proportion of the peak current blocked by nimodipine calculated as $1-\left(\mathrm{I}_{\text {nimodipine }} / \mathrm{I}_{\text {control }}\right)$. D. Sustained potassium current amplitudes measured at the end of each trace were normalized with respect to the sustained current amplitude measured at the end of a pulse to $+80 \mathrm{mV}$ for each individual cell and then averaged. $\mathrm{O}$ end I-V relation measured under control conditions; $\bullet \mathrm{I}-\mathrm{V}$ relation for the sustained current measured in the presence of nimodipine; $\square$ proportion of the sustained current blocked by nimodipine calculated as $1-\left(\mathrm{I}_{\text {nimodipine }} / \mathrm{I}_{\text {control }}\right)$. 
effective but decreased the number of fired APs as well (Chen et al. 2005). In adult rat hippocampal neurons the situation is less equivocal. Magee and Carruth (1999) reported substantial but not complete suppression of the number of APs in series by $10 \mu \mathrm{M}$ nimodipine while Azouz and collaborators, who used anorganic calcium channel blockers (Azouz et al. 1996), did not find any effect of $\mathrm{Ca}^{2+}$ current block on repetitive firing.

The inhibitory effect of LTCC blockers on repetitive firing appears to be species-dependent. In rabbit hippocampal cells, the result of calcium current inhibition was just opposite (Moyer et al. 1992) and application of nimodipine increased the number of APs in series in a concentration- and age-dependent manner. The increase was more pronounced in aging CA1 neurons than in young CA1 neurons consistent with an increased expression of LTCC in aged animals (Moyer and Disterhoft 1994; Campbell et al. 1996; Veng and Browning 2002). In mouse hippocampus, elimination of LTCC either by application of $10 \mu \mathrm{M}( \pm)$ isradipine or by tissue-selective inactivation of the Cav1.2 gene moderately decreased the number of spikes in a train (Moosmang et al. 2005; Lacinova et al. 2008).

The above-cited authors attributed the effect of DHP blockers to their inhibitory action on LTCC. However, the proportion of L-type calcium currents was comparable in all investigated experimental objects being between 25\% (adult mouse hippocampal cells, Lacinova et al. 2008) and 45\% (neonatal rat hippocampal cell, present work), while the DHP effect was highly variable from potentiation (young and old rabbit hippocampus, Moyer et al. 1992) through no effect (adult rat hippocampus, Azouz et al. 1996) to moderate inhibition (adult mouse hippocampus, Lacinova et al. 2008) to almost complete inhibition (young and adult rat hippocampus; Magee and Carruth 1999; Chen et al. 2005). While both $\mathrm{Ca}_{\mathrm{V}} 1.2$ and $\mathrm{Ca}_{\mathrm{V}} 1.3$ channels contribute to total LTCC in mammalian hippocampus (Obermair et al. 2004; Moosmang et al. 2005; Kim et al. 2007; Schlick et al. 2010), their relative contribution depends on species and age. These channels do differ in their sensitivity to DHP, however, this variability may only partly account for reported differences. It is possible that applied DHP blockers act on more than one target.

DHPs were considered to be highly specific blockers of LTCC. More recently it was shown that a number of DHPs may block also T-type calcium channels (Williams et al. 1999; Lacinova et al. 2000; Drigelova et al. 2009; Perez-Reyes et al. 2009), $\mathrm{Na}^{+}$channels (Yatani and Brown 1985; Inoue et al. 1999) and potassium channels (Lin et al. 2001; Gao et al. 2005; Zhang and Gold 2009) at micromolar concentrations. While $\mathrm{Na}^{+}$currents and T-type calcium channels initiate AP firing, potassium channels together with high-voltage activated calcium channels determine the repolarizing phase of AP.

In our model the sodium current was not affected. Block of T-type calcium channels, if any, was included in block of the total calcium current. $\mathrm{K}^{+}$channels were substantially blocked by $10 \mu \mathrm{M}$ nimodipine.
Two types of $\mathrm{K}^{+}$currents $\left(\mathrm{I}_{\mathrm{K}}\right)$ were clearly distinguishable in our model: an A-type current carried by $\mathrm{K}_{\mathrm{V}}$ channels $\left(\mathrm{I}_{\mathrm{KV}}\right)$ and a delayed rectifier current carried by $\mathrm{K}_{\mathrm{Ca}}$ channels $\left(\mathrm{I}_{\mathrm{KCa}}\right) . \mathrm{I}_{\mathrm{KCa}}$ in rat hippocampal cells flows through $\mathrm{BK}$ and SK channels (Tseng-Crank et al. 1994; Gu et al. 2005; Salkoff et al. 2006). In our model, $\mathrm{I}_{\mathrm{KCa}}$ contributed less than $10 \%$ to the peak $\mathrm{I}_{\mathrm{K}}$ current and approximately $50 \%$ to the sustained $\mathrm{I}_{\mathrm{K}}$ current. Nimodipine inhibited around $15 \%$ of $\mathrm{I}_{\mathrm{KCa}}$. This current could be inhibited indirectly due to nimodipine block of LTCC. Nevertheless, while BK channels are coupled to LTCC in mouse neocortex (Sun et al. 2003), in rat hippocampus they are tightly coupled to N-type rather than LTCC (Loane et al. 2007). Therefore we cannot exclude a direct interaction of nimodipine with BK channels. A similar inhibition of the delayed rectifier potassium current by nifedipine was observed in human atrial myocytes (Gao et al. 2005). Inhibition of $\mathrm{I}_{\mathrm{KCa}}$ by either mechanism is likely to contribute to suppression of repetitive AP firing observed in our experiments. This suggestion is supported by the finding that block of BK channel by the selective blocker iberiotoxin reduced the spiking frequency in young adult (4-7 weeks) rat hippocampal CA1 cells (Gu et al. 2007) while selective inhibition of SK channels in the same model failed to affect spiking frequency (Gu et al. 2005).

In our model nimodipine inhibited approximately $35 \%$ of peak $K_{V}$ current and accelerated its decay so that the sustained component of this current was inhibited up to $70 \%$. This finding is in line with several previous reports. In human atrial myocytes 5-30 $\mu \mathrm{M}$ nifedipine inhibited an A-current and accelerated its decay in a manner identical to that found in our work. Additionally, $10 \mu \mathrm{M}$ nifedipine blocked and accelerated an A-current through the $\mathrm{K}_{\mathrm{V}} 1.5$ channel expressed in HEK 293 cells (Lin et al. 2001). In adult dorsal root ganglion neurons, nifedipine and nimodipine inhibited $\mathrm{K}_{\mathrm{V}}$ currents with an $\mathrm{IC}_{50}$ around $10 \mu \mathrm{M}$ (Zhang and Gold 2009). As both $\mathrm{I}_{\mathrm{KV}}$ and $\mathrm{I}_{\mathrm{KCa}}$ contribute to afterhyperpolarization in CNS neurons their inhibition may substantially contribute to suppression of repetitive AP firing by nimodipine observed in our experiments. The inhibition of an A-type potassium current was virtually voltage-independent for depolarizations to $0 \mathrm{mV}$ and higher. However, the decay of the current during the depolarizing pulse was accelerated. These observations, which are in line with findings of Bett and coauthors (Bett et al. 2006), are compatible with an open channel block.

In conclusion, effect of DHPs on the repetitive AP firing in hippocampal neurons is highly species-dependent and partly also age-dependent. This variability is caused by the variability in expression of voltage-gated calcium and/or potassium ion channels. The DHP-induced suppression of all but the first AP in neonatal hippocampal rat neurons reported in this work mimics findings in young rat hippocampal neurons but in adult rat hippocampal cells DHPs were less effective. We suggest that the validity of a statement about the role of individual ion channels in hippocampal 
excitability is restricted to the species and its age investigated. Further, we have shown that effect of DHPs in neonatal rat hippocampal neurons is only partly mediated by inhibition of LTCC. Additional inhibition of voltage- and calcium-dependent potassium channels contributes substantially to this effect. This additional interaction must be taken into account when DHP channel blockers are applied on cells, in which potassium conductance may be active.

Acknowledgement. This work was supported by the Marie Curie Research Training Network CavNET MRTN-CT-2006-035367, and by the Slovak Research and Development Agency under the contract No. APVV-0212-10 and VVCE-0064-07. A. C., B. T., J. R.-R. and L. L. have no conflict of interest and no financial interest in the publication of this manuscript.

\section{References}

Azouz R., Jensen M. S., Yaari Y. (1996): Ionic basis of spike afterdepolarization and burst generation in adult rat hippocampal CA1 pyramidal cells. J. Physiol. 492, 211-223

Bauer E. P., Schafe G. E., LeDoux J. E. (2002): NMDA receptors and L-type voltage-gated calcium channels contribute to long-term potentiation and different components of fear memory formation in the lateral amygdala. J. Neurosci. 22, 5239-5249

Bett G. C., Morales M. J., Strauss H. C., Rasmusson R. L. (2006): KChIP2b modulates the affinity and use-dependent block of Kv4.3 by nifedipine. Biochem. Biophys. Res. Commun. 340, 1167-1177 doi:10.1016/j.bbrc.2005.12.135

Bliss T. V., Lomo T. (1973): Long-lasting potentiation of synaptic transmission in the dentate area of the anaesthetized rabbit following stimulation of the perforant path. J. Physiol. 232, 331-356

Campbell L. W., Hao S. Y., Thibault O., Blalock E. M., Landfield P. W. (1996): Aging changes in voltage-gated calcium currents in hippocampal CA1 neurons. J. Neurosci. 16, 6286-6295

Chen S., Yue C., Yaari Y. (2005): A transitional period of Ca2+-dependent spike afterdepolarization and bursting in developing rat CA1 pyramidal cells. J. Physiol. 567, 79-93 doi:10.1113/jphysiol.2005.084590

Deisseroth K., Mermelstein P. G., Xia H., Tsien R. W. (2003): Signaling from synapse to nucleus: the logic behind the mechanisms. Curr. Opin. Neurobiol. 13, 354-365 doi:10.1016/S0959-4388(03)00076-X

Drigelova M., Tarabova B., Duburs G., Lacinova L. (2009): The dihydropyridine analogue cerebrocrast blocks both T-type and L-type calcium currents. Can. J. Physiol. Pharmacol. 87, 923-932 doi:10.1139/Y09-086

Dudek S. M., Fields R. D. (2002): Somatic APs are sufficient for late-phase LTP-related cell signaling. Proc. Nat. Acad. Sci. U. S. A. $\mathbf{9 9}, 3962-3967$ doi:10.1073/pnas.062510599

Frey U., Krug M., Reymann K. G., Matthies H. (1988): Anisomycin, an inhibitor of protein synthesis, blocks late phases of LTP phenomena in the hippocampal CA1 region in vitro. Brain. Res. 452, 57-65 doi:10.1016/0006-8993(88)90008-X
Gao Z., Sun H., Chiu S. W., Lau C. P., Li G. R. (2005): Effects of diltiazem and nifedipine on transient outward and ultra-rapid delayed rectifier potassium currents in human atrial myocytes. Br. J. Pharmacol. 144, 595-604 doi:10.1038/sj.bjp.0706113

Grover L. M., Teyler T. J. (1990): Two components of long-term potentiation induced by different patterns of afferent activation. Nature 347, 477-479 doi:10.1038/347477a0

Gu N., Vervaeke K., Hu H., Storm J. F. (2005): Kv7/KCNQ/M and $\mathrm{HCN} / \mathrm{h}$, but not $\mathrm{KCa} 2 / \mathrm{SK}$ channels, contribute to the somatic medium after-hyperpolarization and excitability control in CA1 hippocampal pyramidal cells. J. Physiol. 566, 689-715 doi:10.1113/jphysiol.2005.086835

Gu N., Vervaeke K., Storm J. F. (2007): BK potassium channels facilitate high-frequency firing and cause early spike frequency adaptation in rat CA1 hippocampal pyramidal cells. J. Physiol. 580, 859-882 doi:10.1113/jphysiol.2006.126367

Hell J. W., Westenbroek R. E., Warner C., Ahlijanian M. K., Prystay W., Gilbert M. M., Snutch T. P., Catterall W. A. (1993): Identification and differential subcellular localization of the neuronal class C and class D L-type calcium channel al subunits. J. Cell Biol. 123, 949-962 doi:10.1083/jcb.123.4.949

Hoffman D. A., Magee J. C., Colbert C. M., Johnston D. (1997): K+ channel regulation of signal propagation in dendrites of hippocampal pyramidal neurons. Nature. $387,869-875$ doi:10.1038/42571

Inoue Y., Hisatome I., Tsuboi M., Ahmmed G. U., Yatsuhashi T., Uchida K., Yamanouchi Y., Santo Y., Miake J., Tanaka Y., Hamada T., Watanabe M., Igawa O., Yoshida A., Shigemasa C., Makita N., Sato R. (1999): Effects of amlodipine on native cardiac $\mathrm{Na}+$ channels and cloned a-subunits of cardiac $\mathrm{Na}+$ channels. Arzneimittelforschung 49, 394-397

Kampa B. M., Letzkus J. J., Stuart G. J. (2006): Requirement of dendritic calcium spikes for induction of spike-timing-dependent synaptic plasticity. J. Physiol. 574, 283-290 doi:10.1113/jphysiol.2006.111062

Kandel E. R. (2009): The biology of memory: a forty-year perspective. J. Neurosci. 29, 12748-12756 doi:10.1523/JNEUROSCI.3958-09.2009

Kim S., Yun H. M., Baik J. H., Chung K. C., Nah S. Y., Rhim H. (2007): Functional interaction of neuronal Cav1.3 L-type calcium channel with ryanodine receptor type 2 in the rat hippocampus. J. Biol. Chem. 282, 32877-32889 doi:10.1074/jbc.M701418200

Lacinova L., Klugbauer N., Hofmann F. (2000): Regulation of the calcium channel a1 $\mathrm{G}$ subunit by divalent cations and organic blockers. Neuropharmacology. 39, 1254-1266 doi:10.1016/S0028-3908(99)00202-6

Lacinova L., Moosmang S., Langwieser N., Hofmann F., Kleppisch T. (2008): Cav1.2 calcium channels modulate the spiking pattern of hippocampal pyramidal cells. Life Sci. 82, 41-49 doi:10.1016/j.lfs.2007.10.009

Lin S., Wang Z., Fedida D. (2001): Influence of permeating ions on Kv1.5 channel block by nifedipine. Am. J. Physiol. Heart Circ. Physiol. 280, H1160-1172 
Loane D. J., Lima P. A., Marrion N. V. (2007): Co-assembly of Ntype $\mathrm{Ca} 2+$ and $\mathrm{BK}$ channels underlies functional coupling in rat brain. J. Cell Sci. 120, 985-995 doi: $10.1242 /$ jcs. 03399

Magee J. C., Carruth M. (1999): Dendritic voltage-gated ion channels regulate the AP firing mode of hippocampal CA1 pyramidal neurons. J. Neurophysiol. 82, 1895-1901

Moosmang S., Haider N., Klugbauer N., Adelsberger H., Langwieser N., Muller J., Stiess M., Marais E., Schulla V., Lacinova L., Goebbels S., Nave K. A., Storm D. R., Hofmann F., Kleppisch T. (2005): Role of hippocampal Cav1.2 Ca2 + channels in NMDA receptor-independent synaptic plasticity and spatial memory. J. Neurosci. 25, 9883-9892 doi:10.1523/JNEUROSCI.1531-05.2005

Moyer J. R., Jr., Thompson L. T., Black J. P., Disterhoft J. F. (1992): Nimodipine increases excitability of rabbit CA1 pyramidal neurons in an age- and concentration-dependent manner. J. Neurophysiol. 68, 2100-2109

Moyer J. R., Jr., Disterhoft J. F. (1994): Nimodipine decreases calcium APs in rabbit hippocampal CA1 neurons in an age-dependent and concentration-dependent manner. Hippocampus 4, 11-17 doi:10.1002/hipo.450040104

Murphy T. H., Worley P. F., Nakabeppu Y., Christy B., Gastel J., Baraban J. M. (1991): Synaptic regulation of immediate early gene expression in primary cultures of cortical neurons. J. Neurochem. 57, 1862-1872 doi:10.1111/j.1471-4159.1991.tb06396.x

Obermair G. J., Szabo Z., Bourinet E., Flucher B. E. (2004): Differential targeting of the L-type Ca2+ channel alpha $1 \mathrm{C}(\mathrm{CaV} 1.2)$ to synaptic and extrasynaptic compartments in hippocampal neurons. Eur. J. Neurosci. 19, 2109-2122 doi:10.1111/j.0953-816X.2004.03272.x

Perez-Reyes E., Van Deusen A. L., Vitko I. (2009): Molecular pharmacology of human Cav3.2 T-type Ca2+ channels: block by antihypertensives, antiarrhythmics, and their analogs. J. Pharmacol. Exp. Ther. 328, 621-627 doi:10.1124/jpet.108.145672

Salkoff L., Butler A., Ferreira G., Santi C., Wei A. (2006): Highconductance potassium channels of the SLO family. Nat. Rev. Neurosci. 7, 921-931 doi:10.1038/nrn1992

Schlick B., Flucher B. E., Obermair G. J. (2010): Voltage-activated calcium channel expression profiles in mouse brain and cultured hippocampal neurons. Neuroscience 167, 786-798 doi:10.1016/j.neuroscience.2010.02.037
Sinnegger-Brauns M. J., Hetzenauer A., Huber I. G., Renstrom E., Wietzorrek G., Berjukov S., Cavalli M., Walter D., Koschak A., Waldschutz R., Hering S., Bova S., Rorsman P., Pongs O., Singewald N., Striessnig J. J. (2004): Isoform-specific regulation of mood behavior and pancreatic beta cell and cardiovascular function by L-type Ca2+ channels. J. Clin. Invest. 113, $1430-1439$

Spruston N., Schiller Y., Stuart G., Sakmann B. (1995): Activitydependent AP invasion and calcium influx into hippocampal CA1 dendrites. Science 268, 297-300 doi:10.1126/science.7716524

Sun X., Gu X. Q., Haddad G. G. (2003): Calcium influx via L- and Ntype calcium channels activates a transient large-conductance $\mathrm{Ca} 2+$-activated $\mathrm{K}+$ current in mouse neocortical pyramidal neurons. J. Neurosci. 23, 3639-3648

Tseng-Crank J., Foster C. D., Krause J. D., Mertz R., Godinot N., DiChiara T. J., Reinhart P. H. (1994): Cloning, expression, and distribution of functionally distinct $\mathrm{Ca} 2+$-activated $\mathrm{K}+$ channel isoforms from human brain. Neuron 13, 1315-1330 doi:10.1016/0896-6273(94)90418-9

Veng L. M., Browning M. D. (2002): Regionally selective alterations in expression of the a1D subunit (Cav1.3) of L-type calcium channels in the hippocampus of aged rats. Brain. Res. Mol. Brain Res. 107, 120-127 doi:10.1016/S0169-328X(02)00453-9

West A. E., Chen W. G., Dalva M. B., Dolmetsch R. E., Kornhauser J. M., Shaywitz A. J., Takasu M. A., Tao X., Greenberg M. E. (2001): Calcium regulation of neuronal gene expression. Proc. Natl. Acad. Sci. U. S. A. 98, 11024-11031 doi:10.1073/pnas.191352298

Williams M. E., Washburn M. S., Hans M., Urrutia A., Brust P. F., Prodanovich P., Harpold M. M., Stauderman K. A. (1999): Structure and functional characterization of a novel human low-voltage activated calcium channel. J. Neurochem. 72, 791-799 doi:10.1046/j.1471-4159.1999.0720791.x

Yatani A., Brown A. M. (1985): The calcium channel blocker nitrendipine blocks sodium channels in neonatal rat cardiac myocytes. Circ. Res. 56, 868-875

Zhang X. L., Gold M. S. (2009): Dihydropyridine block of voltagedependent $\mathrm{K}+$ currents in rat dorsal root ganglion neurons. Neuroscience 161, 184-194 doi:10.1016/j.neuroscience.2009.03.012

Received: February 2, 2011

Final version accepted: April 5, 2011 